by the Standard Chemical Company for the past four and a half years, and on the basis of figures published by Dr. Charles L. Parsons in the May number of the Journal of Industrial and Engineering Chemistry, it is not evident that the method is satisfactorily efficient, when applied to the treatment of low-grade carnotite ore.

Pittsburgh, Pa., June 3, 1916

Charles H. Viol

\section{SCIENTIFIC BOOKS}

RECENT BOOKS IN MATHEMATICS

Algebraic Invariants. By Leonard Eugene Dickson, Professor of Mathematics, University of Chicago. New York, John Wiley and Sons, 1914. Pp. 100. $\$ 1.25$.

A Treatise on the Theory of Invariants. By Oliver E. Glenn, Ph.D., Professor of Mathematics in the University of Pennsylvania. Boston, Ginn and Company, 1915. Pp. 245. Contributions to the Founding of the Theory of Transfinite Numbers. By Georg Cantor. Translated and Provided with an Introduction and Notes by Philip E. B. Jourdain. Chicago and London, The Open Court Publishing Company, 1915. Pp. 211. \$1.25.

Problems in the Calculus. With Formulas and Suggestions. By David D. LeIB, Ph.D., Instructor in Mathematics in the Sheffield Scientific School of Yale University. Boston and New York, Ginn and Company, 1915. Pp. 224.

Diophantine Analysis. By RoBert D. CARMichael, Assistant Professor of Mathematics in the University of Illinois. New York, John Wiley and Sons, 1915. Pp. 118. Historical Introduction to Mathematical Literature. By G. A. Miller, Professor of Mathematics in the University of Illinois. New York, The Macmillan Company, 1916. Pp. 295.

An invariant is any thing - a property or a relation or an expression or a configurationthat remains unaltered when other things connected with it suffer change. In this very comprehensive but essential meaning of the term, the notion is probably as ancient as the human intellect. Certainly in historic time the appeal of the idea has been universal. It has been said that science may be defined as the quest of invariance. Doubtless that quest is an essential mark of science but it is not peculiar to science. For the problem of invariance, the problem of finding permanence in the midst of change, arises out of the flux of things to confront man in all departments of life. And so it is that the search for what abides is not confined to science but is and always has been the chief enterprise of philosophy and theology and art and jurisprudence. It is, however, in mathematics that the notion of invariance has come to the clearest recognition of its character and significance. In this respect the notion in question has had a history like that of all other great ideas that have slowly and at length become available for the processes of logic.

The oldest and now most elaborate portion of the mathematical doctrine of invariance is about as old as American independence. Though now an imposing theory, its beginning was like a mustard seed. It began, not in ratiocination, but in an observation-mathematics indeed depends ev̀en more upon observation than upon formal reasoning. It began in what was in itself a very small observation, an observation (1773) by Lagrange that the discriminant of the quadratic form $a x^{2}+$ $2 b x y+c y^{2}$ remains unaltered on replacing $x$ by $x+\lambda y$. The next important step was taken by Gauss in 1801 and the next by Boole in 1841. Incited by Boole's beautiful results, the English mathematicians, Cayley and Sylvester, entered the field, the former producing in rapid succession his great memoirs on Quantics and the latter his brilliant investigations in what he conceived more poetically as the Theory of Forms. The interest so aroused quickly passed to the continent engaging the great abilities of such mathematicians as Aronhold, Hermite, Clebsch, Gordan and others. The result is the colossal doctrine variously styled the algebra of quantics, the theory of algebraic invariants and covariants, and the theory of forms.

It is to this doctrine that Professor Dick- 
son's book gives the beginner an admirable introduction. It is, I say, for beginners, for it presupposes only a fair knowledge of analytical geometry and the differential calculus. The book is much larger than it appears to be, being very compactly written, the author having the art of getting a maximum of results with a minimum of talk. Yet the exposition is remarkably clear, uniting the two stylistic virtues of precision and conciseness. The work is composed of three parts. The symbolic notation is reserved for part III. Geometric interpretation is emphasized. In part I. linear transformation is alternately interpreted non-projectively and projectively; that is, on the one hand as working a change of reference configuration, and on the other as merely effecting a lawful transfer of attention from old loci (or envelopes) to new ones referred to the old configuration. Part II., which is mainly concerned with the properties of binary forms, deals with such matters as homogeneity, weight, transformation products, annihilators, linear independence, Hermite's reciprocity law, etc. The canonical form of the quartic is found and the equation is solved. Part III., which occupies 38 of the book's 100 pages, is devoted to a presentation and use of the symbolic method of Aronhold and Clebsch. In passing the author notes that this method is equivalent to the previously invented but relatively cumbrous hyperdeterminant method of Cayley. This part and indeed the book may be said to culminate in Hilbert's theorem regarding the expressibility of the forms of a system in terms of a finite number of them and the use of the theorem in proving the finiteness of a fundamental system of covariants of a set of binary forms.

It seems unfortunate that Professor Dickson did not deem it wise or find it practicable to set forth the matter of this volume in its natural relation to the theory of groups. Perhaps some one will some time write for beginners a book on transformations, groups and invariants with applications.

Professor Glenn's treatise is somewhat more extensive than Professor Dickson's. It, too, is introductory, beginning with a variety of simple considerations. Both the symbolic and the non-symbolic methods are explained and employed. Geometric interpretations are given and some connection with the group concept is made. The book comprises the following nine chapters: the principles of invariant theory (32 pages); properties of invariants (7 pages); the processes of invariant theory (40 pages), dealing with operators, the Aronhold symbolism, reducibility, concomitants in terms of roots, and geometric interpretations; reduction (46 pages), concerned with Gordan's series, the quartic, transvectant systems, syzygies, Hilbert's theorem, Jordan's lemma, and grade; Gordan's theorem (16 pages), giving proof of the theorem and illustration by the cubic and quartic; fundamental systems (16 pages); combinants and rational curves (13 pages); seminvariants and modular invariants (32 pages); and invariants of ternary forms (25 pages). There is added an appendix of ten pages devoted to exercises.

With access to the foregoing books, to Salmon's classic book, and to such recent British works as that by Grace and Young and Elliott's "Algebra of Quantics," the Englishspeaking student can not complain of having to resort to other languages for a knowledge of this classic branch of modern algebra.

Many readers, including mathematicians and philosophers, will be grateful to Mr. Jourdain for his excellent translation of Cantor's famous memoirs of 1895 and 1897. These were published in the Mathematische Annalen under the title, "Beiträge zur Begründung der transfiniten Mengenlehre." The translator's rendering of the title is justified by the content of the memoirs. This content is not likely to be fully intelligible to any but such as have mastered Cantor's earlier works beginning in 1870. The value of the volume is much increased by the translator's Introduction of 82 pages sketching the development of function theory in the course of the last century and by the notes he has appended dealing with the growth of the theory of transfinite numbers since 1897.

Dr. Leib's collection of problems presents a good list under each important theme dealt 
with in a first course in the calculus. But few of the problems have been worked out fully and the devising of geometric figures has been left to the student under the guidance of the text he is using or of his instructor, but numerous cautionary and directive explanations are given clearly and concisely, usually at the beginnings of the various problem lists. The answers to typical exercises of each list are given, but a large percentage of the problems are unanswered. Such a collection of exercises ought to make it practicable to teach the elements of the calculus by means of lectures or by means of thin books confined mainly to a presentation of theory.

There are two special reasons why the appearance of Professor Carmichael's beautiful book should be noted in this journal. One is that the subject treated has made a most extraordinary appeal in all scientific times and places. With the exception of geometry, astronomy and logic, hardly any other technically scientific subject has better served to tie together so many centuries, for interest in it probably antedates the school of Pythagoras. The second reason is that a certain long-outstanding problem of Diophantine analysis has recently come to very popular fame by virtue of the extraordinary prize of $\$ 25,000$ provided by the German mathematician Wollfskehl for its solution. The problem is to prove the so-called Last Theorem of Fermat (1601-1665) stated by him without proof on the margin of a page of his copy of a fragment of the "Arithmetica" of the Greek mathematician Diophantos. The theorem is: If $n$ is an integer greater than 2 there do not exist integers $x, y, z$, all different from zero, such that $x^{n}+y^{n}=z^{n}$. The prize, the offer of which does not expire till September 13, 2007 , will be awarded to one who proves that the theorem is not universally true (if it is not) and who at the same time determines all values of $n$ for which it is true. Long before the prize was announced the problem engaged the efforts of great mathematicians and thus led to important developments in the theory of numbers. Since the announcement thousands of the mathematically innocent have assailed the problem. If these innocents could have had access to such a book as Professor Carmichael's where the nature of the problem is explained and the present state of knowledge regarding it is sketched, they might have been deterred from wasting their time and that of others.

The rendering of such a service was not, however, the author's aim. There is scarcely another branch of mathematics in which the results achieved in course of the centuries are so special, fragmentary and isolated. Professor Carmichael's aim was two-fold, namely, to produce for beginners an introduction to Diophantine analysis and to bring its fragmentary and scattered discoveries into organic unity. And he has succeeded admirably. The style is excellent. The content and scope of the book are fairly well indicated by the titles and lengths of its six chapters: Introduction, rational triangles, the method of infinite descent (22 pages); problems involving a multiplicative domain (30 pages); equations of third degree (20 pages); equation of fourth degree (10 pages); higher equations, the Fermat problem (17 pages); the method of functional equations (9 pages). The theory thus actually presented and the judiciously selected exercises make the work available for private reading as well as for a short university course in the subject.

Professor Miller's “ Historical Introduction to Mathematical Literature" grew out of a course of lectures designed to supplement regular instruction. It thus employs a more or less expansive style and seeks to be "synoptic and inspirational" for such as may not lay claim to much mathematical discipline. It is guided by a highly commendable aim: namely, to conduct the reader to commanding points of view so that he may judge for himself whether the fields he is thus enabled to glimpse invite him to further exploration. The aim is pursued with a notable optimism despite the nation-wide depreciatory utterances of such educational leaders and agitators as Commissioner Snedden and Abraham Flexner. Professor Miller believes that "shameless ignorance" of mathematics "does not represent a 
normal condition on the part of those interested in the history of the human race." We are also told that "with our gradual evolution from the state of barbarism the history of war and bloodshed is being slowly replaced by that of political and intellectual movements." From which we infer that that portion of the preface was composed prior to August, 1914.

Believing that history courses for secondaryschool teachers should be more largely concerned with modern developments than is their wont, Professor Miller particularly stresses these developments, though the content of his discourse is in very considerable measure drawn also from ancient and medieval times.

The 35 pages of the initial chapter are devoted to sketching the progress made from the beginning of the nineteenth century to the present time in mathematical intelligence, mathematical research, mathematical history and mathematical teaching. In particular the fact is pointed out that the rapid and continuously increasing American mathematical activity during the last twoscore years has placed our country among the leading mathematical countries of the world. If we have not yet produced a mathematician of the very first rank, we can at least claim to have produced men of notable ability and productiveness.

Chapter II. (42 pages) presents a large amount of interesting information respecting types of recent literature, societies, international congresses, periodicals, works of reference, mathematical tables and collected works. In the 51 pages of the third chapter we have a rather meager discussion of definitions of the term mathematics; a historical account of the manner in which the science has acquired its grand divisions and subdivisions; a quite too brief but interesting account of the advent, influence and position of a few "dominant concepts" such as irrational quantities, equation solution, function, group, matrix, domain of rationality; some instructive remarks and historical references respecting mathematical terminology and notation; a short section on errors in mathematical literature; a section, entitled living mathematicians, arguing with feeling and good judgment the importance of devising suitable means for determining "Who is Who" among mathematicians; and a final section treating inadequately, hardly more than touching, the now pressing question of mathematics as an educational subject.

There follow three chapters dealing with "fundamental developments" respectively in arithmetic, in geometry and in algebra. Of these the first (29 pages) opens with Euclid's proof that the number of prime numbers is infinite; explains the Sieve of Eratosthenes; sketches the history and appraises the significance of irrational numbers, giving (doubtless unintentionally) the impression (p. 133) that these numbers admit of only negative definition; treats briefly the fundamental operations of arithmetic, then of notation systems, and closes with a short and excellent account of the Fermat theorem. The next chapter (23 pages) devotes to "fundamental developments in geometry" three sections, one to the Pythagorean theorem, one to the area and volume of the sphere, and one to the triangle. A valuable chapter (22 pages) on algebra is historically rich in its handling of the fundamental theorem of algebra, the notion of determinant, numerical equations, domains of rationality, the beginnings of invariant theory, and the tale of the binomial theorem.

Chapter VII., somewhat oddly entitled "Twenty-five Prominent Deceased Mathematicians," is the largest and most interesting division of Professor Miller's interesting book. It contains a very readable account of the following men selected from among the great mathematicians of the world: Euclid, Archimedes, Apollonius, Diophantus, Vieta, Descartes, Fermat, Newton, Leibniz, Euler, Lagrange, Gauss, Cauchy, Steiner, Abel, Hamilton, Galois, Sylvester, Weierstrass, Cayley, Hermite, Kronecker, Cremona, Lie, Poincaré.

The book closes with a list, accompanied with brief characterizations, of a large number of bibliographies, reference works, and books on the history, and the teaching and philosophy of mathematics.

Cassius J. Keyser 